Jurusan Fisika FMIPA Univ. Riau Pekanbaru p-ISSN.1412-2960 | e-2579-521X

\title{
PENENTUAN DENSITAS SPESIES PLASMA HIDROGEN PADA KESETIMBANGAN TERMODINAMIK TEKANAN ATMOSFIR MENGGUNAKAN MATLAB
}

\author{
Reeky Fardinata, Saktioto \\ Jurusan Fisika \\ Fakultas Matematika dan Ilmu Pengetahuan Alam, \\ Universitas Riau Kampus Bina Widya \\ Jl. Prof. Muchtar Lutfi Pekanbaru, 28293, Indonesia \\ *E-mail korespondensi: reekyfardi@gmail.com
}

\begin{abstract}
Thermal equilibrium hydrogen plasma at atmospheric pressure were simulated using the software matrix laboratory (MATLAB). Runge Kutta method numerical method as a settlement of differensial model equations of chemical kibetik with the arrhenius equation approach and continuity equations so that the equilibrium density values for each species were obtained. Equilibrium hydrogen plasma at atmospheric pressure and density rate review every reaction involved. Parameter of ionizing $\mathrm{nH}^{+} / \mathrm{nH}_{2}^{+} \approx 0,2$ and disasosiasi $n / \mathrm{nH}_{2} \approx 1$ as a reference equilibrium plasma. Equilibrium plasma is found in time interval $10^{-6}-10^{-3} \mathrm{~s}$ thermal hydrogen plasmas with temperatures of $1 \mathrm{eV}$. The density of hydrogen plasma thermal equilibrium overall are in the interval of $10^{14} \mathrm{~m}^{-3}-10^{20} \mathrm{~m}^{-3}$. The reaction rate of each species varies based on the type of collision and rate of change of species.
\end{abstract}

Keywords: Plasma hydrogen thermal, Simulation, Equilibrium, The reaction rate

\begin{abstract}
ABSTRAK
Kesetimbangan plasma hidrogen termal pada tekanan atmosfir disimulasikan menggunakanperangkat lunak Matrix Laboratory (MATLAB). Metode numerik Runge Kutta sebagai langkah penyelesaian persamaan differensial dari model kibetik kimia dengan pendekatan persamaan arrhenius dan persamaan kontinuitas sehingga nilai densitas kesetimbangan untuk setiap spesies diperoleh. Kesetimbangan plasma hidrogen pada tekanan atmosfir meninjau kerapatan spesies hidrogen serta laju dari setiap reaksi yang terlibat. Parameter ionisasi $\mathrm{nH}^{+} / \mathrm{nH}_{2}^{+} \approx 0,2$ dan disosiasi $n \quad / \mathrm{nH}_{2} \approx 1$ sebagai acuan kesetimbangan plasma. Kesetimbangan plasma didapati dalam interval waktu $10^{-6}-10^{-3} \mathrm{~s}$ dengan temperatur plasma hidrogen termal sebesar $1 \mathrm{eV}$. Densitas kesetimbangan plasma hidrogen termal keseluruhan berada dalam interval $10^{14} \mathrm{~m}^{-3}-10^{20} \mathrm{~m}^{-3}$. Laju reaksi dari setiap spesies bevariasi berdasarkan jenis tumbukan dan laju perubahan spesies
\end{abstract}

Kata kunci: Plasma Hidrogen Termal, Simulasi, Kesetimbangan, densitas, laju reaksi

Diterima 30-08-2019| Disetujui 30-09-2019| Dipublikasi 31-10-2019

\section{PENDAHULUAN}

Spesies plasma terdiri dari spesies atomik, molekul, ion dan elektron. Spesies plasma ditinjau untuk menentukan kesetimbangan dalam plasma. Plasma hidrogen tekanan atmosfir pada penelitian, meninjau beberapa spesies yang terdiri dari elektron, $\mathrm{H}, \mathrm{H}_{2}, \mathrm{H}^{+}$, $\mathrm{H}^{-}$dan $\mathrm{H}_{2}^{+}$. Spesies-spesies tersebut akan saling bertumbukan di dalam system hingga mencapai kondisi setimbang. Tumbukan antar spesies - spesies tersebut disebabkan oleh beberapa faktor salah satunya adalah temperatur. Tumbukan yang terjadi antar spesies yang semakin banyak akan mempengaruhi jumlah densitas setiap spesies hidrogen.Gas hidrogen dimanfaatkan dalam plasma diantaranya adalah teknologi micro 
plasma[8], pencegah korosi[2] plasma etching [1], pemanfaatan bidang medis[10]dan pendeteksi tingkat keasaman lingkungan [9]. Plasma hidrogen pada tekanan atmosfir dapat dianalisa dengan meninjau kesetimbangan densitas spesies yang terdapat pada plasma.

\section{TINJAUAN PUSTAKA}

Plasma merupakan percampuran kuasi netral dari elektron, radikal, ion positif dan ion negatif. Kondisi kuasinetral merupakan daerah dimana terdapat kerapatan ion $\left(\mathrm{n}_{\mathrm{i}}\right)$ yang hampir sama dengan kerapatan elektron $\left(\mathrm{n}_{\mathrm{e}}\right)$ sehingga dapat dikatakan $\mathrm{n}_{\mathrm{i}} \approx \mathrm{n}_{\mathrm{e}} \approx \mathrm{n}$, dengan $\mathrm{n}$ menyatakan kerapatan secara umum yang disebut kerapatan plasma.

Temperatur Plasma dinyatakan dalam satuan $\mathrm{eV}$ dengan mengkonversi satuan kelvin.

$$
k(K) \equiv e T^{\prime}(e)
$$

Persamaan kontinuitas tanpa dimensi digunakan sebagai model kinetik kimia hidrogen

$$
\frac{\partial \mathrm{n}}{\partial \mathrm{t}}=\mathrm{S}
$$

Persamaan 2 menyatakan perubahan densitas terhadap waktu hanya bergantung pada laju produksi spesies per satuan volume (S).

Suatu reaksi dapat dinyatakan oleh persamaan berikut [3]:

$$
\mathrm{aA}+\mathrm{bB} \rightarrow \mathrm{cC}+\mathrm{dD}+\ldots
$$

Sedangkan, laju reaksi maju diberikan oleh:

$$
\mathrm{R}_{\mathrm{t}}=\mathrm{k}_{\mathrm{t}}\left(\mathrm{n}_{\mathrm{A}}\right)^{\mathrm{a}}\left(\mathrm{n}_{\mathrm{B}}\right)^{\mathrm{t}}
$$

Laju reaksi balik diberikan oleh :

$$
\mathrm{R}_{\mathrm{r}}=\mathrm{k}_{\mathrm{r}}\left(\mathrm{n}_{\square}\right)^{\mathrm{I}}\left(\mathrm{n}_{\mathrm{L}}\right)^{\llbracket} \ldots
$$

$$
\text { Persamaan Arrhenius }
$$
modifikasi didefinisikan untuk memperjelas kebergantungan faktor pra-eksponensial pada suhu [3]. Persamaan Arrhenius modifikasi dapat ditulis dalam bentuk

$$
\mathrm{k}=\alpha\left(\frac{T}{3}\right)^{\beta} \exp \left(\frac{-\gamma}{\mathrm{T}}\right)
$$

Konstanta $\alpha, \beta$, dan $\gamma$ dalam persamaan (5), merupakan parameter Arrhenius, yang nilainya bergantung pada hasil eksperimen.
Laju produksi spesies $\mathrm{C}$ persatuan volume untuk setiap reaksi dalam persamaan reaksi (5), diberikan oleh:

$$
\mathrm{S}_{\mathrm{C}}=\left(\mathrm{R}_{\mathrm{t}} \times \mathrm{c}\right)-\left(\mathrm{R}_{\mathrm{r}} \times 0\right)
$$

Secara umum, laju produksi spesies per satuan volume untuk setiap reaksi dapat dihitung menurut persamaan berikut:

$$
\mathrm{S}=\left(\mathrm{M}_{\mathrm{r}}-\mathrm{N}_{\mathrm{t}}\right)\left(\mathrm{R}_{\mathrm{t}}-\mathrm{R}_{\mathrm{r}}\right)
$$

Dimana $\mathrm{M}_{\mathrm{r}}$ dan $\mathrm{N}_{\mathrm{f}}$ berturut turut adalah jumlah molekul spesies hasil reaksi dan pereaksi [3].

\section{METODE PENELITIAN}

Gambar 1. dapat dilihat proses keseluruhan dari penelitian hingga akhir

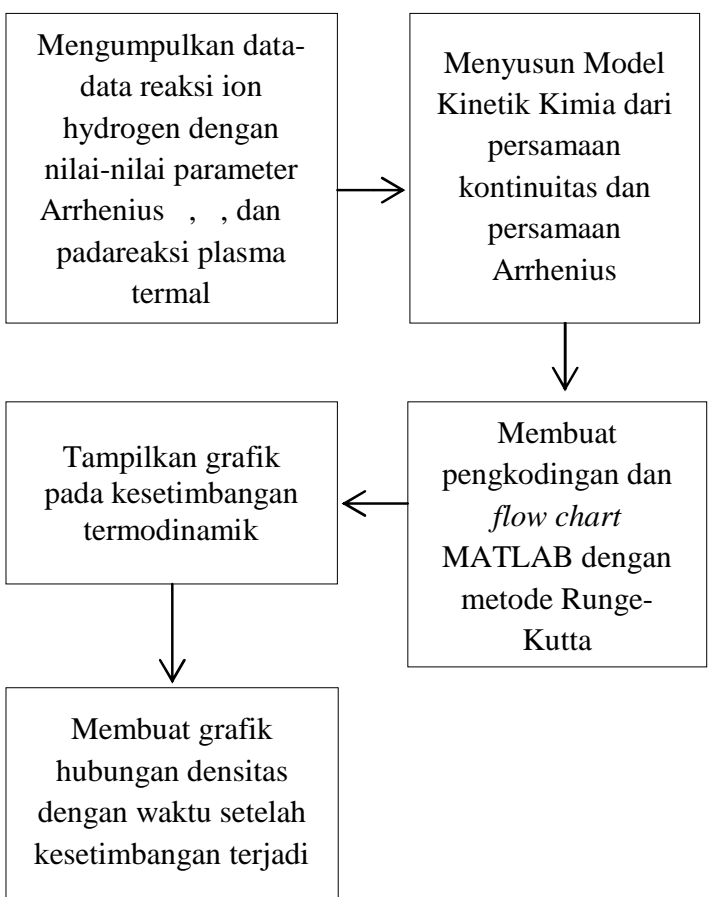

Gambar 1. Diagram alir penelitian

\section{HASIL DAN PEMBAHASAN}

Spesies plasma hidrogen termal mengalami kesetimbanganpada saat $1,451 \times 10^{-6} \mathrm{~s}$. Densitas spesies hidrogen yang signifikan dialami oleh spesies hidrogen monoatomik $(\mathrm{H})$ dan spesies ion positif hidrogen atomik $\left(\mathrm{H}^{+}\right)$yang mengalami penurunan sepanjang waktu tumbukan. Gambar 2 menunjukkan perubahan densitas spesies saat mencapai kondisi setimbang. 
Tabel 1. Reaksi spesies hidrogen termal

\begin{tabular}{|c|c|c|c|c|}
\hline $\begin{array}{l}\text { No. } \\
\text { Reaksi }\end{array}$ & Reaksi & $\alpha$ & $\beta$ & $\begin{array}{c}\gamma \\
(\mathrm{K})\end{array}$ \\
\hline 1 & $\mathrm{H}+\mathrm{e}^{-} \rightarrow \mathrm{H}^{+}+\mathrm{e}^{-}+\mathrm{e}^{-}$ & $1,14 \times 10^{-15}$ & 0,21 & 169000 \\
\hline 2 & $\mathrm{H}^{+}+\mathrm{e}^{-}+\mathrm{e}^{-} \rightarrow \mathrm{H}+\mathrm{e}^{-}$ & $7,08 \times 10^{27}$ & $-4,5$ & 0 \\
\hline 3 & $\mathrm{H}+\mathrm{H}_{2} \rightarrow \mathrm{H}_{2}+\mathrm{H}$ & $6,3 \times 10^{5}$ & 0,5 & 4000 \\
\hline 4 & $\mathrm{H}_{2}+\mathrm{H} \rightarrow \mathrm{H}+\mathrm{H}_{2}$ & $6,3 \times 10^{5}$ & 0,5 & 4000 \\
\hline 5 & $\mathrm{H}_{2}+\mathrm{H} \rightarrow \mathrm{H}+\mathrm{H}+\mathrm{H}$ & $4,49 \times 10^{-14}$ & $-0,1$ & 52530 \\
\hline 6 & $\mathrm{H}+\mathrm{H}+\mathrm{H} \rightarrow \mathrm{H}_{2}+\mathrm{H}$ & $8,8 \times 10^{-45}$ & 0 & 0 \\
\hline 7 & $\mathrm{H}_{2}+\mathrm{H}_{2} \rightarrow \mathrm{H}+\mathrm{H}+\mathrm{H}_{2}$ & $1,43 \times 10^{-12}$ & -0.7 & 52530 \\
\hline 8 & $\mathrm{H}+\mathrm{H}+\mathrm{H}_{2} \rightarrow \mathrm{H}_{2}+\mathrm{H}_{2}$ & $2,8 \times 10^{-43}$ & $-0,6$ & 0 \\
\hline 9 & $\mathrm{H}_{2}+\mathrm{e}^{-} \rightarrow \mathrm{H}+\mathrm{H}+\mathrm{e}^{-}$ & $1,91 \times 10^{-1}$ & 1,0 & 116045 \\
\hline 10 & $\mathrm{H}_{2}^{+}+\mathrm{H}_{2}+\mathrm{e}^{-} \rightarrow \mathrm{H}_{2}+\mathrm{H}_{2}$ & $6,07 \times 10^{-34}$ & $-2,5$ & 0 \\
\hline 11 & $\mathrm{H}^{+}+\mathrm{H}_{2}+\mathrm{e}^{-} \rightarrow \mathrm{H}_{2}+\mathrm{H}$ & $6,07 \times 10^{-34}$ & $-2,5$ & 0 \\
\hline 12 & $\mathrm{H}+\mathrm{H}_{2}^{+}+\mathrm{e}^{-} \rightarrow \mathrm{H}+\mathrm{H}_{2}$ & $1,66 \times 10^{-35}$ & $-2,5$ & 0 \\
\hline 13 & $\mathrm{H}^{+}+\mathrm{H}+\mathrm{e}^{-} \rightarrow \mathrm{H}+\mathrm{H}$ & $1,66 \times 10^{-35}$ & $-2,5$ & 0 \\
\hline 14 & $\mathrm{H}+\mathrm{H} \rightarrow \mathrm{H}^{+}+\mathrm{H}+\mathrm{e}^{-}$ & $6,5 \times 10^{3}$ & $-3,8$ & 159000 \\
\hline 15 & $\mathrm{H}_{2}+\mathrm{e}^{-} \rightarrow \mathrm{H}_{2}^{+}+\mathrm{e}^{-}+\mathrm{e}^{-}$ & $9,53 \times 10^{-19}$ & 0,9 & 145000 \\
\hline 16 & $\mathrm{H}^{-}+\mathrm{H} \rightarrow \mathrm{H}_{2}+\mathrm{e}^{-}$ & $7,83 \times 10^{2}$ & 0 & 0 \\
\hline 17 & $\mathrm{H}^{+}+\mathrm{H}^{-} \rightarrow \mathrm{H}+\mathrm{H}$ & $1,3 \times 10^{6}$ & $-0,5$ & 0 \\
\hline
\end{tabular}

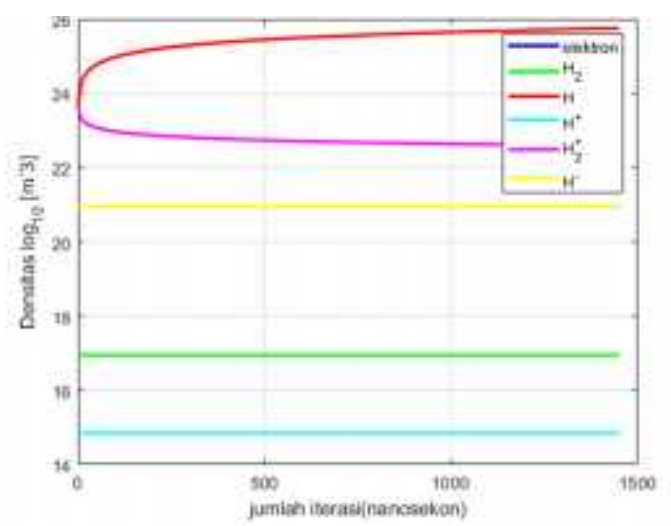

Gambar 2. Perubahan densitas spesies plasma.

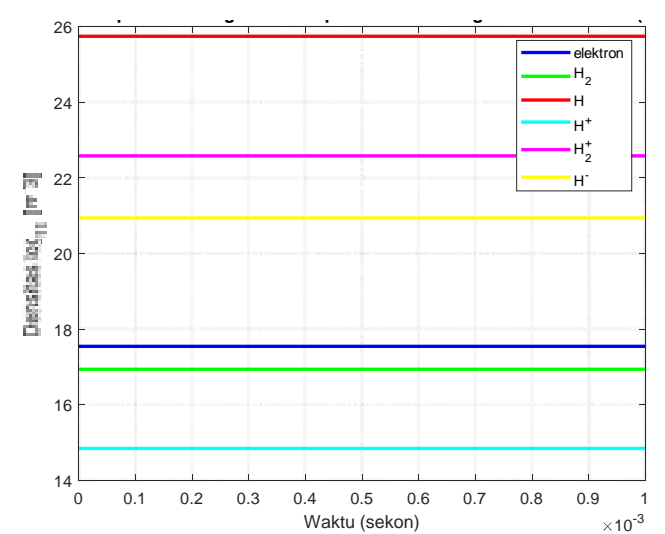

Gambar 3. Densitas spesies hidrogen termal pada kesetimbangan termodinamik (1 atm).

Waktu kesetimbangan plasma terjadi dalam rentang waktu $10^{-6}-10^{-3} \mathrm{~s}$ [2].
Kesetimbangan plasma diperlihatkan oleh gambar 2.

Tabel 2. Densitas spesies hidrogen termalpada kesetimbangan termodinamik.

\begin{tabular}{ccc}
\hline No & Spesies & $\begin{array}{c}\text { Densitas spesies } \\
\text { dalam } \log 10\left(\mathrm{~m}^{-3}\right)\end{array}$ \\
\hline 1 & Elektron & 17.5471 \\
2 & $\mathrm{H} 2$ & 16.9440 \\
3 & $\mathrm{H}$ & 25.7517 \\
4 & $\mathrm{H}^{+}$ & 14.8471 \\
5 & $\mathrm{H}^{2+}$ & 22.5804 \\
6 & $\mathrm{H}^{-}$ & 20.9461 \\
\hline
\end{tabular}

Tabel 2. menyajikan nilai kesetimbangan densitas spesies plasma hidrogen termal. Nilai densitas kesetimbangan elektron yang berhasil dicatat oleh matlab adalah $3.5245 \times 10^{17} \mathrm{~m}^{-3}$ Elektron dalam penelitian ini telah memenuhi karakteristik plasma sehingga elektron dianggap bergerak bebas dan tanpa mengalami gangguan medan dari luar. Densitas elektron yang diperoleh masih dalam kategori yang sesuai dengan karakteristik plasma laboratorium yaitu tidak melebihi $10^{5}$ sampai $10^{15} \mathrm{~m}^{-3}$ dengan rentang suhu 11604 Kelvin [2].

Spesies hidrogen hidrogen diatomik $\left(\mathrm{H}_{2}\right)$ dan hidrogen monoatomik (H) yang disebabkan oleh proses disosiasi dapat dianalisa sengan membandingkan kedua 
spesies tersebut $\left(\mathrm{nH}_{/ \mathrm{nH}_{2}} \approx 1\right)$ [6].Spesies ion plasma hidrogen dihasilkan dari proses ionisasi pada saat reaksi, produksi spesies ion plasma $\mathrm{H}^{+}$dan $\mathrm{H}_{2}^{+}$sama sama dihasikan oleh spesies atom hidrogen, oleh karena kedua spesies ini dihasilkan proses yang sama, maka dapat dibuat perbandingan antara kedua spesies ion positif ini. $n H^{+} / n H_{2}^{+} \approx 0,2$ parameter perbandingan menunjukkan bahwa produksi spesies ion plasma dari proses ionisasi dan disosiasi ion terhadap spesies molekul hidrogen telah memenuhi tingat ionisasi pada plasma [6].

Tabel 3. Nilai laju reaksi spesies hidrogen

\begin{tabular}{|c|c|c|}
\hline No. & Reaksi & $\begin{array}{l}\text { Laju Reaksi } \\
\left(\mathrm{m}^{-3} \mathrm{~s}^{-1}\right)\end{array}$ \\
\hline 1 & $\mathrm{H}+\mathrm{e}^{-} \rightarrow \mathrm{H}^{+}+\mathrm{e}^{-}+\mathrm{e}^{-}$ & $2,313 \times 10^{22}$ \\
\hline 2 & $\mathrm{H}^{+}+\mathrm{e}^{-}+\mathrm{e}^{-} \rightarrow \mathrm{H}+\mathrm{e}^{-}$ & $1,138 \times 10^{72}$ \\
\hline 3 & $\mathrm{H}+\mathrm{H}_{2} \rightarrow \mathrm{H}_{2}+\mathrm{H}$ & $1,377 \times 10^{49}$ \\
\hline 4 & $\mathrm{H}_{2}+\mathrm{H} \rightarrow \mathrm{H}+\mathrm{H}_{2}$ & $1,377 \times 10^{49}$ \\
\hline 5 & $\mathrm{H}_{2}+\mathrm{H} \rightarrow \mathrm{H}+\mathrm{H}+\mathrm{H}$ & $1,672 \times 10^{27}$ \\
\hline 6 & $\mathrm{H}+\mathrm{H}+\mathrm{H} \rightarrow \mathrm{H}_{2}+\mathrm{H}$ & $1,188 \times 10^{31}$ \\
\hline 7 & $\begin{array}{l}\mathrm{H}_{2}+\mathrm{H}_{2} \rightarrow \mathrm{H}+\mathrm{H}+ \\
\mathrm{H}_{2}\end{array}$ & $9,251 \times 10^{18}$ \\
\hline 8 & $\begin{array}{l}\mathrm{H}+\mathrm{H}+\mathrm{H}_{2} \rightarrow \mathrm{H}_{2}+ \\
\mathrm{H}_{2}\end{array}$ & $9,464 \times 10^{22}$ \\
\hline 9 & $\mathrm{H}_{2}+\mathrm{e}^{-} \rightarrow \mathrm{H}+\mathrm{H}+\mathrm{e}^{-}$ & $1,039 \times 10^{31}$ \\
\hline 10 & $\begin{array}{l}\mathrm{H}_{2}^{+}+\mathrm{H}_{2}+\mathrm{e}^{-} \rightarrow \mathrm{H}_{2}+ \\
\mathrm{H}_{2}\end{array}$ & $1,785 \times 10^{18}$ \\
\hline 11 & $\begin{array}{l}\mathrm{H}^{+}+\mathrm{H}_{2}+\mathrm{e}^{-} \rightarrow \mathrm{H}_{2}+ \\
\mathrm{H}\end{array}$ & $7,691 \times 10^{19}$ \\
\hline 12 & $\begin{array}{l}\mathrm{H}+\mathrm{H}_{2}^{+}+\mathrm{e}^{-} \rightarrow \mathrm{H}+ \\
\mathrm{H}_{2}\end{array}$ & $3,135 \times 10^{25}$ \\
\hline 13 & $\mathrm{H}^{+}+\mathrm{H}+\mathrm{e}^{-} \rightarrow \mathrm{H}+\mathrm{H}$ & $1,351 \times 10^{27}$ \\
\hline 14 & $\mathrm{H}+\mathrm{H} \rightarrow \mathrm{H}^{+}+\mathrm{H}+\mathrm{e}^{-}$ & $1.922 \times 10^{49}$ \\
\hline 15 & $\mathrm{H}_{2}+\mathrm{e}^{-} \rightarrow \mathrm{H}_{2}^{+}+\mathrm{e}^{-}+\mathrm{e}^{-}$ & $2.967 \times 10^{12}$ \\
\hline 16 & $\mathrm{H}^{-}+\mathrm{H} \rightarrow \mathrm{H}_{2}+\mathrm{e}^{-}$ & $3.108 \times 10^{43}$ \\
\hline 17 & $\mathrm{H}^{+}+\mathrm{H}^{-} \rightarrow \mathrm{H}+\mathrm{H}$ & $5.594 \times 10^{42}$ \\
\hline
\end{tabular}

Nilai laju reaksi ditunjukkan oleh tabel 3, dengan nilai reaksi tertinggi adalah reaksi rekombinasi (reaksi 2) $1,138 \times 10^{72} \mathrm{~m}^{-3} \mathrm{~s}^{-1}$, laju reaksi terkecil dicapai oleh ionisasi (reaksi 16), yaitu $2.967 \times 10^{12} \mathrm{~m}^{-3} \mathrm{~s}^{-1}$. Laju reaksi ionisasi plasma hidrogen termal lebih rendah dibandingkan dengan laju rekombinasi. Plasma hidrogen termal bergantung pada temperatur elektron yang nilainya hampir sama dengan temperatur spesies lainnya [5].

\section{KESIMPULAN}

Kesetimbangan plasma hidrogen termal mencapai kestabilan $1,451 \times 10^{-6} \mathrm{~s}$ dan berlangsung selama $10^{-6}-10^{-3} \mathrm{~s}$. Densitas dari masing masing spesies elektron, $\mathrm{H}, \mathrm{H}_{2}, \mathrm{H}^{+}, \mathrm{H}_{2}{ }^{+}$ dan $\mathrm{H}^{-}$berturut-turut adalah $10^{17,5471} \mathrm{~m}^{-3}$, $10^{16,9440} \mathrm{~m}^{-3}, 10^{25,7517} \mathrm{~m}^{-3}, 10^{14,8471} \mathrm{~m}^{-3}, 10^{22,5804} \mathrm{~m}^{-}$ 3 dan $10^{20.9461} \mathrm{~m}^{-3}$.Parameter ionisasi plasma diperoleh $n H^{+} / n H_{2}^{+} \approx 0,2$ dan parameter disosiasi adalah $n / n H_{2} \approx 1$. Kesetimbangan dalam plasma akan meningkatkan disosiasi dan berlangsung secara cepat dan dalam fraksi yang kecil. Laju reaksi tertinggi adalah reaksi rekombinasi (reaksi 2) $1,138 \times 10^{72} \mathrm{~m}^{-3} \mathrm{~s}^{-1}$, laju reaksi terkecil dicapai oleh ionisasi (reaksi 16), yaitu $2.967 \times 10^{12} \mathrm{~m}^{-3} \mathrm{~s}^{-1}$.

\section{REFERENSI}

1. Germaschewski, K. et al. (2016) 'The Plasma Simulation Code: A modern particle-in-cell code with patch-based load-balancing, Journal of Computational Physics. Elsevier Inc., 318, pp. 305-326. doi: 10.1016/j.jcp.2016.05.013.

2. Inui, H. et al. (2010). Measurement of Hydrogen Radical Density and Its Impact on Reduction of Copper Oxide in Atmospheric-Pressure Remote Plasma Using $\mathrm{H}_{2}$ and Ar Mixture Gases. Applied Physics Express 3, 126101.

3. Ismail, F. D. et al. (2011) 'Optik Thermodynamic equilibrium for nitrogen species discharge: Comparison with global model', Optik - International Journal for Light and Electron Optics. Elsevier GmbH., 122(5), pp. 455-458. doi: 10.1016/j.ijleo.2010.03.006.

4. J. Henriques, N. et al,. (2011). Microwave plasma torches driven by surface wave applied for hydrogen production. Hydrogen Energy.36:345-354.

5. J. Jolly and J.-P. Booth. (2005). Atomic hydrogen densities in capacitively coupled very highfrequency plasmas in $H$ : Effect of excitation frequency. J. Appl. Phys. 97, 103305 (6pp). 
6. M. Sode, et al. (2013). 'Ion chemistry in H 2 -Ar low temperature plasmas', 063302. doi: $10.1063 / 1.4817526$

7. Narendra Singh. et al. (2018). Characterization of hot dense plasma with plasma parameters. Radiation Physics and Chemistry 146, 105-114.

8. Parigger, C. G. et al. (2014) 'Spectrochimica Acta Part B Asymmetric hydrogen beta electron density diagnostics of laser-induced plasma', Spectrochimica Acta Part B: Atomic
Spectroscopy. Elsevier B.V., 99(September 2013), pp. 28-33. doi: 10.1016/j.sab.2014.06.013.

9. Rauscher, H. et al. (2010). Plasma Technology for Hyperfunctional Surfaces. Germany: Wiley-VCH Verlag GmbH \& Co.

10. Rossi, F. et al. (2008). Use of a lowpressure plasma discharge for the decontamination and sterilization of medical devices. Pure Applied Chemistry Vol. 80, No. 9, 1939-1951 